\title{
The Ice-resistant Performance Analysis of Cable Pipe for Offshore Booster Station
}

\author{
Yebin Zhao ${ }^{1}$, Rui Dong ${ }^{2}$, Baolin Tong ${ }^{2}$, Yongfei Liu ${ }^{3}$, Dayong Zhang ${ }^{2,4} *$ \\ ${ }^{1}$ Shandong Electric Power Engineering Consulting Institute Co. Ltd., Jinan, Shandong, China \\ ${ }^{2}$ School of Ocean Science and Technology, Dalian University of Technology Panjin, Liaoning, China \\ ${ }^{3}$ College of Arts and Information Engineering, Dalian Polytechnic University, Dalian, Liaoning, China \\ ${ }^{4}$ Ningbo Institute of Dalian University of Technology, Ningbo, Zhejiang, China \\ *Corresponding Author.
}

\begin{abstract}
In order to verify the ice-resistant performance of offshore booster station and its cable pipe. Taking a wind farm in Bohai as an an example, the response of offshore booster station and its cable pipe under the condition of sea ice once in 100 years is analyzed by numerical simulation. The results show that the platform and its cable pipe of the booster station have certain anti ice performance, but under extreme ice load, the vibration response of the upper part of the platform is large, so the safety operation of the facilities and cable pipes should be protected.
\end{abstract}

Keywords: Booster station, ice load, cable pipe, ice induced vibration

\section{Introduction}

In recent years, offshore wind power has been developing continuously. As the power collection, boosting, distribution and control center of offshore wind farms, offshore boosting stations occupy the core position in the whole project [1]. The booster station intensively boosts and converts the electric energy generated by the fan and transmits it to the shore to reduce the electric energy loss. According to the data released by the Global Wind Energy Council (GWEC) on February 25, 2021, the newly installed offshore wind power in the world will exceeded 6 GWin 2020, and the newly added offshore wind power grid-connected capacity in China exceeded 3 $\mathrm{GW}$, accounting for half of the global increase. At present, China's offshore wind farms are mainly located in the sea area about $10 \mathrm{~km}$ away from the coast, and the booster station at sea should be constructed at the same time. For the wind farms built in the Yellow Sea and Bohai Sea in China, the winter sea ice load will become the control load, and the offshore wind power foundation, booster station and other infrastructure should have certain ice-resistanceperformance. The booster stations in Bohai Sea are mostly jacket structure, which connects the upper module with the seabed pile foundation. The jacket structure has many forms such as single leg, three legs and four legs[2].

The analysis of ice-resistance performance of booster station has been successfully practiced. Zuo et al.[3] used DUT-1 model ice to carry out the dynamic model test of booster station in different ice coming directions, and obtained the prototype ice force time history through similarity ratio conversion. Based on that, they analyzed the response of the booster station. Yanget al.[4] analyzed the response of structure under static and dynamic ice load by comparing booster station with oil and gas platforms in Bohai. The analysis of ice-resistance performance of booster stationin the icy sea area in cold regionmainly focuses on the jacket leg of platform.In fact, cable pipe will also directly interact with sea ice, which has not attracted enough attention.

ISSN: 0010-8189

(C) CONVERTER 2021 
The cable tube of the booster station platform is similar to the offshore riser in terms of structural mechanical properties and belongs to a flexible structure. Yanget al. proposed a method to calculate the dynamic response of vortex-induced vibration, and studied the influence of vortex-induced vibration on the strength of drilling risers through a simplified analysis model [5].Based on the long-term prototype monitoring data, Liu Ming et al. established a wave model for the dynamic design of underwater structures [6]. Hrteet al. studied the impact of environmental uncertainty on drilling riser fatigue, and finally proposed a method to calculate the fatigue of the riser system [7]. Hu et al. studied the reliability analysis of marine risers under long-term corrosion conditions, and proposed a reliability analysis method [8]. At present, there is not much research on the ice resistance performance of offshore risers. The main reason is that the stiffness of the riser is small, the interaction mechanism between sea ice and this kind of flexible structure is not perfect, and there is a lack of suitable ice load model. The ice load is very sensitive to the size and shape of the structure, because different shapes and sizes will lead to different failure modes of the ice plate [9-11].

\section{Cable Pipe Characteristic Analysis}

Figure 1 shows the offshore booster station. The cable pipes of the booster station are mostly fixed on the pile legs of the station, which are used to protect cables and ensure power transmission.

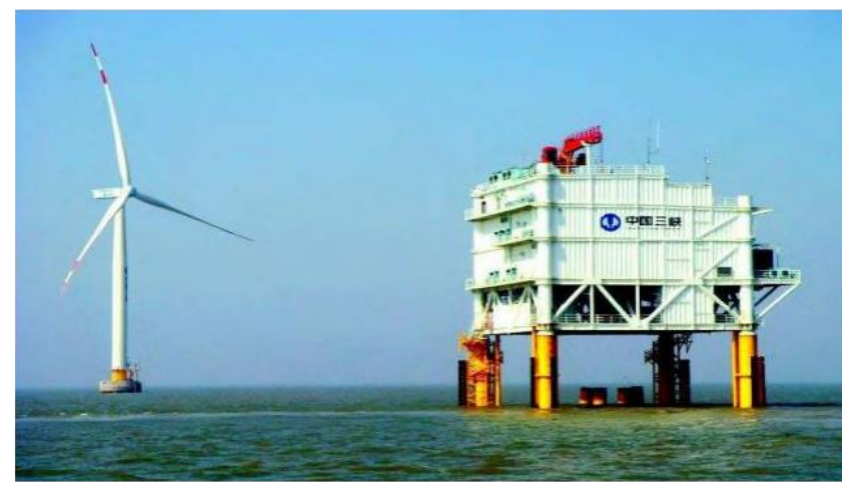

Fig1: Offshore booster station

The fundamental frequency of offshore booster station structure is generally around $1 \mathrm{~Hz}$. Based on on-site sea ice monitoring, it is found that the energy spectrum frequency of ice breaking with jacket platform is mostly between $0 \mathrm{~Hz}$ and $1 \mathrm{~Hz}$. The natural period of the station is very close to the ice force period, which is easy to produce ice-induced resonance and has significant dynamic effect. To clarify the dynamic characteristics of the cable pipe, modal analysis is carried out on the cable pipe according to the structural parameters of a typical cable pipe (see Figure 2). Two cable pipes $(\varphi 508 \times 20 \mathrm{~mm})$ and $(\varphi 325 \times 20 \mathrm{~mm})$ are connected to the pile legs of the platform, and the cable pipes are connected with the pile legs of the platform through fixed steel pipes. A structural model is established based on ANSYS, in which SHELL181 unit is used for cable pipes and BEAM188 unit is used for fixing steel pipes. The stiffness of the joint between the fixed steel pipe and the pile leg is adjusted in all directions by COMBIN14 unit, so that the stiffness of the joint is the same as that of the joint of the original booster station pile leg. The established finite element model is shown in Figure 3 . The left side of the model is $\varphi 508 \times 20 \mathrm{~mm}$ cable pipe, and the right side is $\varphi 325 \times 20 \mathrm{~mm}$ cable pipe.

ISSN: 0010-8189

(C) CONVERTER 2021 


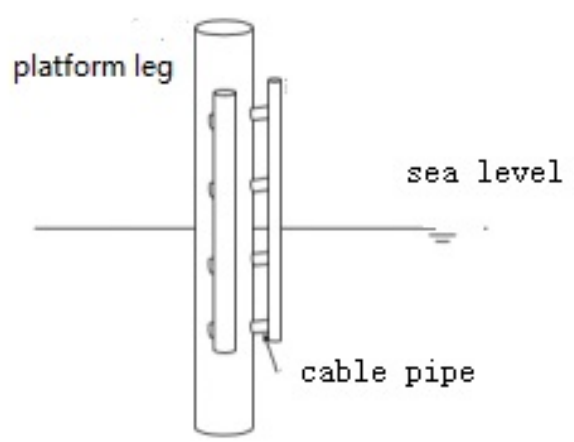

Fig 2: Cable pipe diagram of offshore booster station

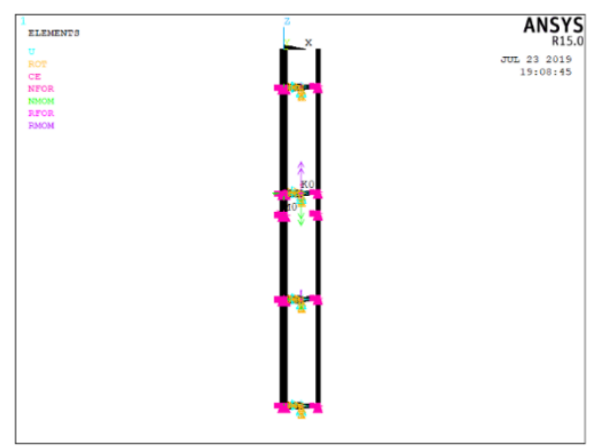

Fig 3: Finite element model of cable pipe

The frequencies of first three orders of cable pipe are obtained by modal analysis, and the results are shown in Table 1.

Table 1 frequencies of first three orders of cable pipe

\begin{tabular}{|c|c|c|c|}
\hline Order & Frequency/Hz & Order & Frequency/Hz \\
\hline 1 & 13.853 & 3 & 15.465 \\
\hline 2 & 14.696 & & \\
\hline
\end{tabular}

It can be seen from Table 1 that the fundamental frequency of the cable pipe is about $14 \mathrm{~Hz}$, which is quite different from the sea ice breaking frequency.Therefore, the cable pipe is unlikely to have strong ice-induced resonance. However, if the whole platform has ice-induced steady-state vibration, the response of the cable pipe needs to be analyzed and checked.

There are two ways to analyze the ice-resistance performance of the cable pipe of the booster station: 1) The cable pipe is modeled separately in the above way, and the mechanical characteristics of the structure are analyzed and the strength check is carried out. This method is simple and convenient, but still has some problems. As the cable pipe is connected to the pile leg of the platform through fixed steel pipes, the station will produce displacement response and vibration response under the action of sea ice, and the overall displacement of the platform will also affect the response of the cable pipe; 2 ) The platform and its cable pipe are modeled as a whole, and loads are applied to the pile legs and cable pipes respectively. The calculated results are closer to the real situation.

The movement of the station will have an impact on the response of the cable pipe, while the installation of the cable pipe will not have an obvious impact on the dynamic characteristics of the platform. If the sea ice acts

ISSN: 0010-8189

(C) CONVERTER 2021 
before the pile leg, it will break ahead of time, and even reduce the ice-induced vibration response of the station. Therefore, if the cable pipe strength is satisfied, the establishment of the outer cable pipe will reduce the probability of ice-induced steady-state vibration of the platform.

\section{Calculation Method of Static Load and Dynamic Load of Sea Ice}

\subsection{Extreme ice force model of vertical structure}

Extreme static ice force is the first problem to be considered in ice-resistance analysis of marine structures. When the sea ice acts on the vertical structure, there will be a variety of failure forms, which are mainly crushing, and the crushing is the most harmful to the structure[12]. For vertical structures, the breaking forms of sea ice are different with the width of structures. When sea ice interacts with a wide structure, they will not be destroyed at the same time.But when it interacts with a narrow structure, they will be destroyed at the same time. If they are destroyed at the same time, the static ice force on the structure will increase. Through years' monitoring of Bohai jacket platform, it is found that the legs of Bohai offshore platform are of narrow structure, and the action of sea ice on the legs of platform will cause simultaneous destroy[13]. The booster station is similar to Bohai jacket platform in form, so the response of booster station under extreme static ice force can also be calculated according to the relevant equation of API-RP-2N code:

$$
F=k D h \sigma_{\mathrm{c}}(1)
$$

Wherein: $F$ is the total ice force, in $\mathrm{N} ; k$ is the reduction factor, which ranges from 0.3 to 0.7 and can be taken as 0.7 for conservative reasons; $D$ is the structure diameter, in $\mathrm{m} ; h$ is ice thickness, in $\mathrm{m}$; ${ }_{\mathrm{c}}$ is the uniaxial compressive strength of sea ice in this area, in MPa. The uniaxial compressive strength of sea ice in Bohai Sea can be approximately taken as $2.0 \mathrm{MPa}$.

\subsection{Self-excited vibration model of upright structure}

Compared with static ice load, dynamic ice load is more harmful to the structure. In a specific range of ice velocity, the frequency of ice force is close to the natural frequency of the structure, and ice-induced steady-state vibration will occur in the structure. When the structure vibrates in steady state, the simplified triangular wave time-domain function can be used to characterize the ice force that produces self-excited vibration[14], and the simplified steady-state ice force model is shown in Figure 4. In Figure 4: $F_{\max }$ is the maximum ice force, which can be conservatively taken as the extreme static ice force; $F_{\text {mean }}$ is the average ice force; $T$ is the ice force period, which can be approximated as the natural period of the structure; is the loading stage coefficient, and 0.8 is recommended; $F$ is the ice force amplitude.

$$
\Delta F=q F_{\max }
$$

Wherein: $q$ is the coefficient, and 0.4 is recommended.

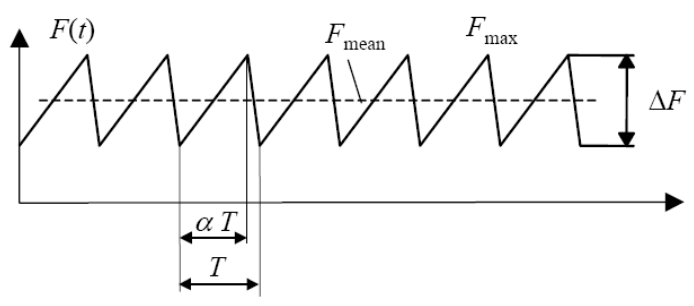

Fig4: Simplified steady-state ice force model

\section{Ice-Resistance Performance Analysis of Cable Pipe of Booster Station under Extreme Ice Conditions}

According to the structural parameters of booster station, the structural model is established based on ANSYS,

ISSN: 0010-8189

(C) CONVERTER 2021 
in which SHELL181 unit is used for the foundation of booster station, including pile legs and cable pipes; BEAM188 unit is used for I-beam of jacket platform, and MASS21 unit is used for counterweight of upper facilities of thestation;the pile foundation is treated by 6 times of pile diameter method, and the part below the mud surface with depth greater than 6 times of foundation diameter is fixed and restrained when modeling; the action position of flat ice is the average horizontal plane position, and the finite element model is shown in Figure 5.

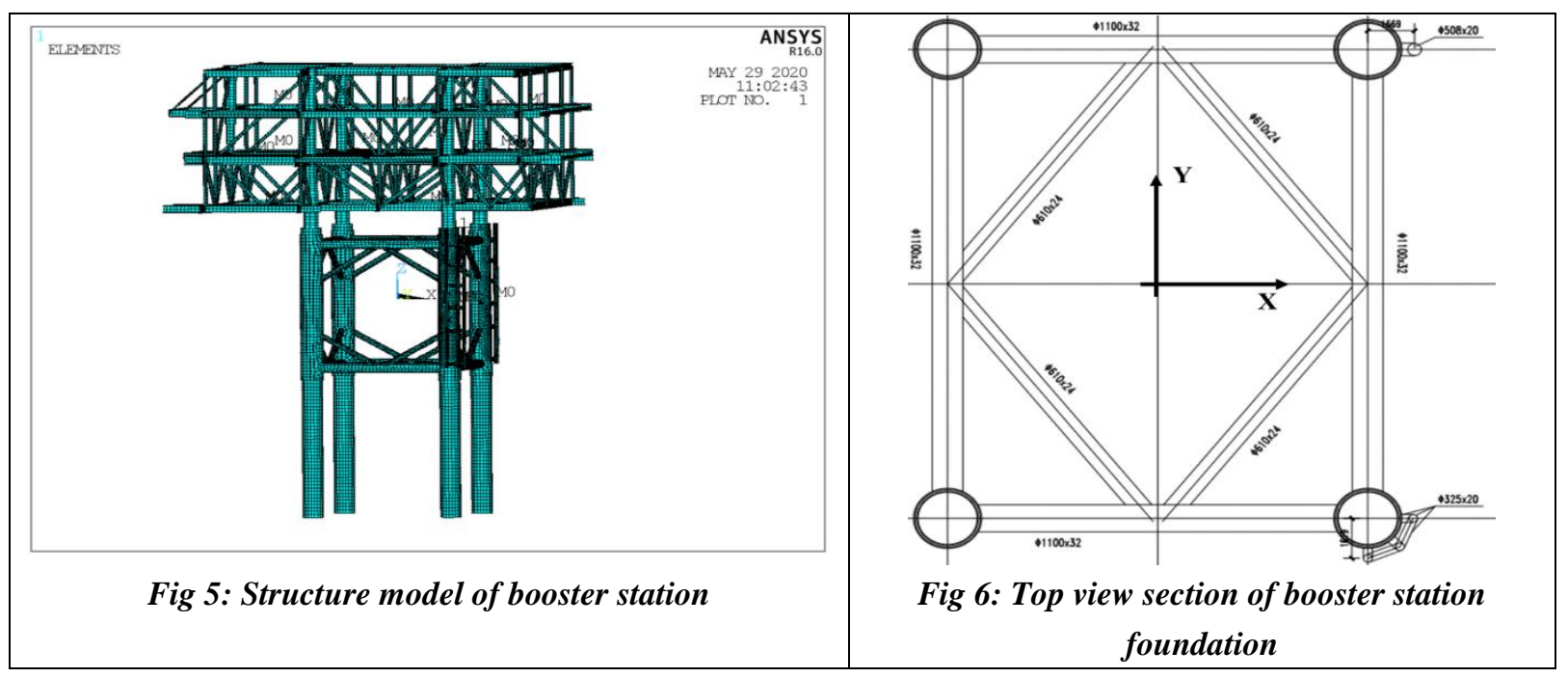

Figure 6 shows the top sectional view of jacket foundation of the booster station, and two kinds of cable pipes with different diameters are fixed on the pile legs. Cable pipe $\mathrm{A}(\varphi 508 \times 20 \mathrm{~mm})$ and 3 cable pipes $\mathrm{B}(\varphi 325 \times 20 \mathrm{~mm})$. Due to the influence of cable pipe, under the coordinate system in the figure, the stress forms and responses of the platform in different ice directions are different, as follows:

1) In the positive direction of $x$-axis, the right leg breaks ice, and there is no cable pipe breaking ice in advance, so the platform is prone to steady vibration. The response under dynamic ice load needs to be analyzed emphatically.

2) In the negative direction of $X$-axis, the right leg and cable pipe play the ice-breaking role, and the extreme static ice force is relatively large, but ice-induced steady-state vibration is not easy to occur.

3) In the positive direction of $Y$ axis, the legs and some cable pipes play the role of breaking ice.

4) In the negative direction of $Y$ axis, the upper cable pipes and the two legs break ice, but the cable pipesare not in front of the legs. The flat ice may still cause ice-induced steady-state vibration of the structure.

According to the relevant requirements of Offshore Boost Station Platform Guide (2019), the return period of design environmental conditions should generally not be less than 50 years. For the sake of conservatism, the response of platform and its cable pipe under static and dynamic ice loads in different ice directions once every 100 years is analyzed.

\subsection{Analysis of extreme static ice force response}

Combined with the research results of extreme static ice load in Section 2.1, the deformation and stress analysis of the maximum extreme static ice force of the fan under the once-in-a-century ice condition are carried out, and the calculation parameters are shown in Table 2. 
CONVERTER MAGAZINE

Volume 2021, No. 5

Table 2 Once-in-a-century extreme ice force of jacket foundation of boost station

\begin{tabular}{|c|c|c|c|}
\hline Part & $\begin{array}{c}\text { Extreme static ice } \\
\text { force/kN }\end{array}$ & Part & Extreme static ice force $/ \mathrm{kN}$ \\
\hline Leg & 1157.100 & Cable pipe B & 154.245 \\
\hline Cable pipe A & 241.097 & & \\
\hline
\end{tabular}

The common ice coming directions of this wind farm are negative $\mathrm{x}$ direction and negative y direction. Extreme ice force is applied to pile legs and cable pipes facing the ice surface for calculation. The calculation results of displacement extremum and stress extremum of the whole structure of booster station and cable pipes are shown in Table 3. See Figure 7 and Figure 8 for displacement nephogram and Mises stress nephogram under once-in-a-century ice condition.

Table 3 Static ice force response in two directions

\begin{tabular}{|c|c|c|c|}
\hline \multirow{4}{*}{ Item } & Displacement extremum/mm & Stress extremum/MPa \\
\hline \multirow{3}{*}{ negative x direction } & Overall & 27.29 & 83.50 \\
\cline { 2 - 4 } & Cable pipe A & 26.26 & 29.92 \\
\cline { 2 - 4 } & Cable pipe B & 23.17 & 37.11 \\
\hline \multirow{3}{*}{ negative y direction } & Overall & 29.26 & 83.46 \\
\cline { 2 - 4 } & Cable pipe A & 29.10 & 39.10 \\
\cline { 2 - 4 } & Cable pipe B & 26.51 & 9.27 \\
\hline
\end{tabular}

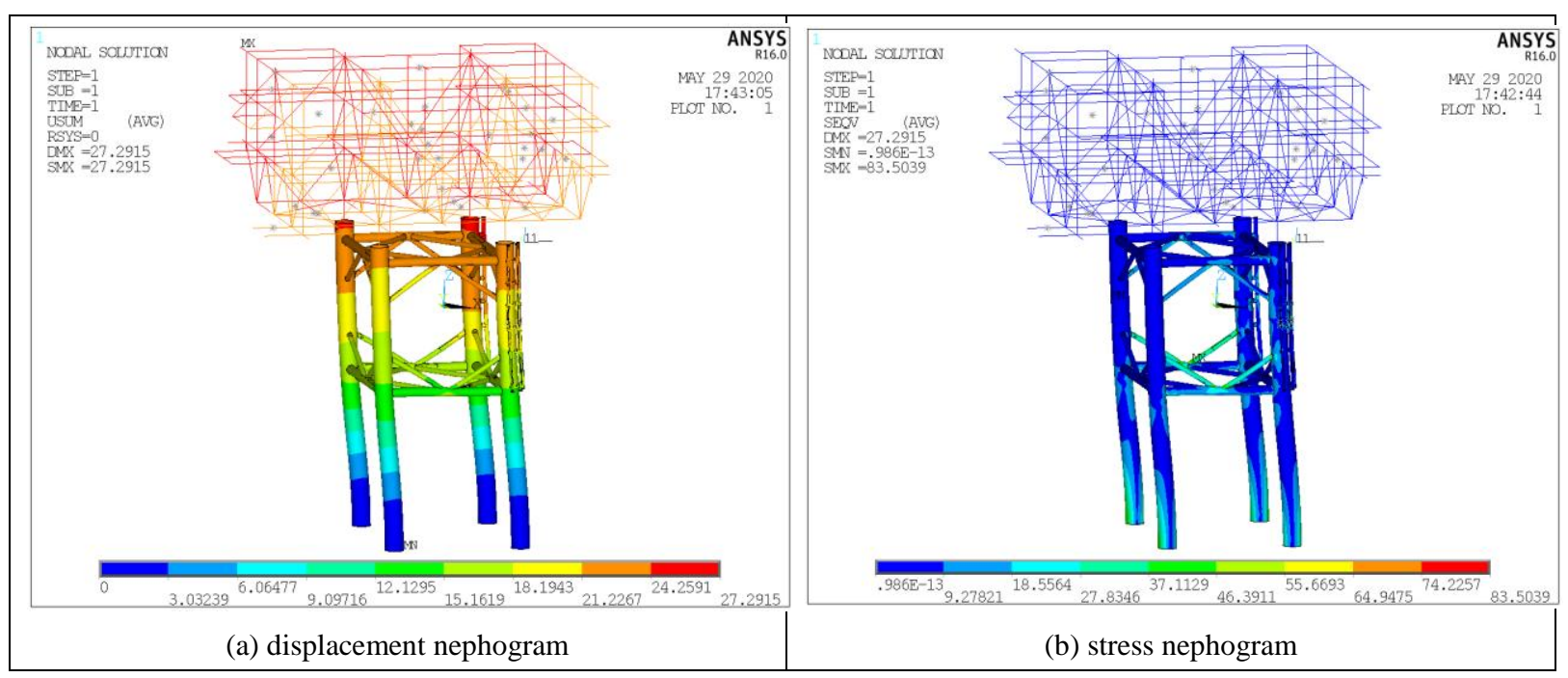

Fig 7: Nephogram of static response in negative xdirection 


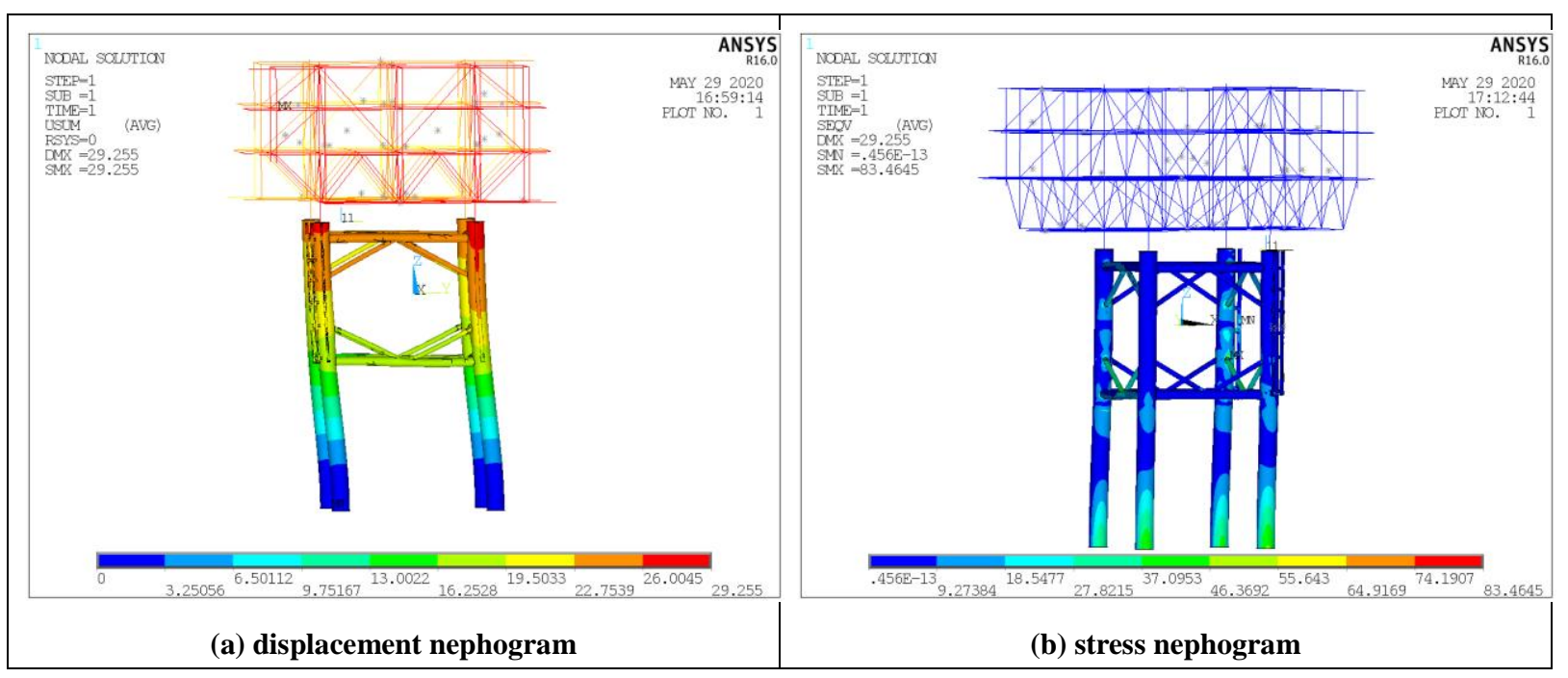

Fig 8: Nephogram of static response in negative ydirection

It can be seen from Table 3 that the displacement response of the whole structure and cable pipe of the booster station is small under two ice coming directions; the larger Mises stress is located at the joint of pile leg, cross brace and diagonal brace of booster station foundation, and the maximum Mises stress is only 83.5 MPa, which is obviously less than the yield stress of offshore steel. The structure has enough strength reserve under the action of once-in-a-century extreme static ice force.

\subsection{Ice vibration response analysis of foundation structure of boost station}

For dynamic response analysis of booster station foundation structure, modal analysis is firstly carried out to obtain the frequencies and vibration shapesof first three ordersof the booster station. The results are shown in Table 4.

Table 4 Frequencies of first three orders of structure

\begin{tabular}{|c|c|c|}
\hline First-order secondary & Third-order frequency & Third-order frequency \\
\hline $0.768 \mathrm{~Hz}$ & $0.7778 \mathrm{~Hz}$ & $0.970 \mathrm{~Hz}$ \\
\hline
\end{tabular}

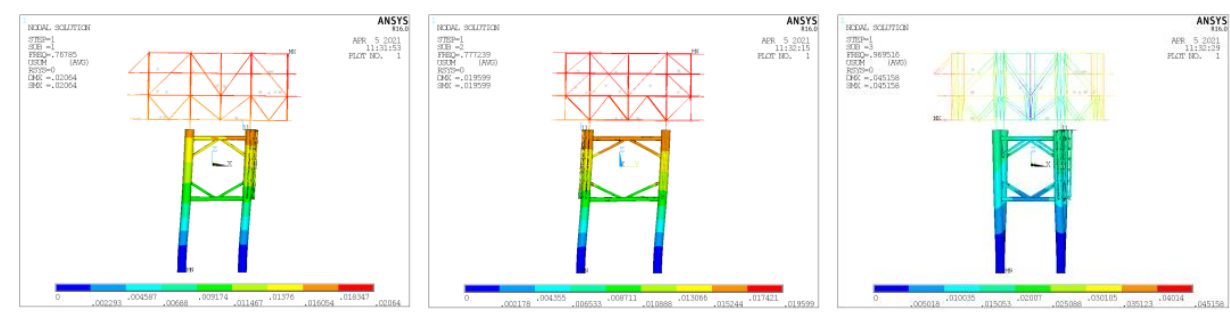

(a) first-order formation diagram (b) second-order formation diagram (c) third-order formation diagram Fig9: Formation diagram of first three orders the structure

It can be seen from Table 4 and Figure 9 that the first-order frequency of the booster station is $0.768 \mathrm{~Hz}$, and the formations of first threeorders of the structure are $\mathrm{x}$-axis swing, $\mathrm{y}$-axis swing and structural torsion respectively. Based on the steady-state ice force model of vertical structure in Section 2.2, the ice force function is determined and the dynamic ice force time history of booster station is calculated. For the sake of conservation, the corresponding dynamic ice forces are applied at the ice force acting points of pile legs and cable pipes respectively. With ANSYS transient analysis method, the damping ratio of the structure is 0.02 , and the time step is $0.1 \mathrm{~s}$. The ice force time history of the platform under the once-in-100-year ice condition is calculated,

ISSN: 0010-8189

(C) CONVERTER 2021 
and the responses of the upper part of the platform and the cable pipe of the booster station are extracted and analyzed. The results are summarized in Table 5 and Table 6 respectively.

Table 5 Steady-state vibration response in negative $x$ direction (once-in-100-year)

\begin{tabular}{|c|c|c|c|}
\hline Classification & $\begin{array}{c}\text { Maximum displacement } \\
/ \mathrm{mm}\end{array}$ & $\begin{array}{c}\text { Maximum acceleration } \\
/\left(\mathrm{mm} / \mathrm{s}^{2}\right)\end{array}$ & Maximum stress/MPa \\
\hline Cable pipe A & 37.93 & 490.09 & 9.34 \\
\hline Cable pipe B & 37.06 & 514.07 & 10.17 \\
\hline Upper platform & 50.39 & 770.25 & - \\
\hline
\end{tabular}

Table 6 Steady-state vibration response in negative y direction (once-in-100-year)

\begin{tabular}{|c|c|c|c|}
\hline Classification & $\begin{array}{c}\text { Maximum displacement } \\
\text { amplitude } / \mathrm{mm}\end{array}$ & $\begin{array}{c}\text { Maximum } \\
\text { accelerationamplitude } \\
/\left(\mathrm{mm} / \mathrm{s}^{2}\right)\end{array}$ & $\begin{array}{c}\text { Maximum stress } \\
\text { amplitude } / \mathrm{MPa}\end{array}$ \\
\hline Cable pipe A & 42.93 & 569.34 & 17.66 \\
\hline Cable pipe B & 41.73 & 574.73 & 6.16 \\
\hline Upper platform & 58.41 & 867.14 & - \\
\hline
\end{tabular}

It can be seen from Table 3, Table 5 and Table 6 that compared with the structural displacement response under the action of extreme static ice force, the structural displacement response of the booster station under steady-state vibration increases under various ice conditions. The maximum displacement amplitude is 58.41 $\mathrm{mm}$, which still meets the relevant design requirements.

Compared with the displacement extremum, the displacement response is increased. Steady vibration occurs in the booster station, and the structural displacement response is small under various ice conditions. The vibration response in negative $\mathrm{y}$ direction of ice force direction is slightly larger than that in negative $\mathrm{x}$ direction. The acceleration amplitudes of cable pipesare all below $600 \mathrm{~mm} / \mathrm{s}^{2}$, which meets the early warning standard of ice-induced vibration of platform structure in Guide for Analysis of Ice-induced Vibration and Ice-induced Fatigue of Fixed Offshore Steel Structures (2018). If a once-in-a-centurysteady-state vibration ice condition occurs, the amplitude of vibration acceleration on the upper part of the platform will exceed $600 \mathrm{~mm} / \mathrm{s}^{2}$, which will affect the health of the staff in the station and threaten the normal operation of the upper facilities. If this happens, it is recommended to take ice-breaking measures.

\section{Conclusion}

1. The fundamental frequency of cable pipe is large, and is much higher than the energy spectrum frequency of sea ice breaking. The ice-induced steady-state vibration is not easy to occur.

2. The installation of cable pipe will break the flat ice before it interacts with the platform leg, which can reduce the occurrence probability of ice-induced vibration.

3. The ice-resistance performance of a proposed booster station and its cable pipe under static ice load and dynamic ice load in two common ice coming directions is analyzed. Under the static ice load, the platform and cable pipe have high safety reserve, which meets the design requirements.

4. Under the condition of ice-induced steady sea ice once every 100 years, the station's foundation structure of booster station has certain ice-resistance performance, but the vibration response of the upper part of the station is severe, so ice-breaking measures should be taken to ensure the normal operation of the upper facilities and the safety of cable pipes.

ISSN: 0010-8189

(C) CONVERTER 2021 


\section{Acknowledgements}

This study was supported by the National Natural Science Foundation of China (52071055), National Key Research and Development Program (2017YFF0210700), and Innovation team of colleges and universities in Liaoning Province (LT2019004).

\section{References}

[1] J. Liao, "Ultimate strength analysis for offshore substation platform structure," Building Structure, vol. 50(S1), pp. 230-233, 2020.

[2] H. U. Bin, Z.Luo, “General Design for Offshore Substation. Guangdong Shipbuilding”, 2018.

[3] J. Zuo, X. Li,W. Wang, et al., "SAFETY ASSESSMENT OF OFFSHORE SUBSTATION PLATFORM UNDER EXTREME ICE CONDITIONS,” Acta Energiae Solaris Sinica, 2018.

[4] Y.P. Yang, D.Y. Zhang, C.J. Lou, et al.,"Analysis of the Structural Ice-resistant Performance for the Booster Station Platform in the Bohai Sea," Ship \& Ocean Engineering, 2015.

[5] J. Yang, C. Liu,H. Liu, et al., "Strength and stability analysis of deep sea drilling riser," Petroleum Science,vol. 4, no. 2, 2007.

[6] L. Ming, S. Y. Y, W. H. W, et al., "Current models for strength and dynamic design of underwater structures," Ocean Engineering, pp. 186, 2019.

[7] T. Hrte, G. Grytyr, M. Russo, et al.,"Wellhead Fatigue: Effect of Directional and Annual Variation in Weather for a Sequence of Drilling Operations: ASME 2015 34th International Conference on Ocean, Offshore and Arctic Engineering", 2015.

[8] X. Hu,C. Zhou, M. Duan, et al.,"Reliability analysis of marine risers with narrow and long corrosion defects under combined loads,” Petroleum Science, vol.11, no. 01, pp. 139-146, 2014.

[9] Sanderson, "Ice mechanics: Risks to offshore structures," London, UK: Graham \& Trotman, 1988.

[10] Schulson,"Brittle failure of ice,” Engineering fracture mechanics, vol. 68,pp.1889-1921, 2001.

[11] Q.J. Yue, F.W. Guo, T.Kärnä,"Dynamic Ice Forces of Slender Vertical Structures due to Ice Crushing,”Cold Regions Science and Technology, vol. 56,pp. 77-83, 2009.

[12] S.F. Wang, "Research on Anti-ice Vibration Design of Wind TurbineFoundation Structure in Ice Region,"Dalian, 2020.

[13] D.Y. Zhang, G.J. Wang, S.F. Wang, et al.,"Ice-resistant performance analysis of offshore wind turbine foundation in ice zone," Chuan Bo Li Xue/Journal of Ship Mechanics, vol. 22, no. 5, pp. 615-627, 2018.

[14] T.ÄRNÄ, K.KAMESAKI, H.TSUKUDA, “A Numerical Model for Dynamic Ice-Structure Interaction,” Computers and Structures, vol. 72, no. 4, pp. 645-658,1999. 